\title{
A preliminary study on the navigation capacity improvement of the Yangtze River Waterway based on the joint dispatching optimization of the upstream reservoir group
}

\author{
Yingjian $\mathrm{Chen}^{1, \mathrm{a}}$, Qiaoping $\mathrm{Fu}^{1}$ and Fangkai $\mathrm{Ma}^{1}$ \\ ${ }^{1}$ Changiiang Institute of Survey, Planning, Design and Research, Wuhan 430010, China
}

\begin{abstract}
The Yangtze River, which has the largest freight volume in the world, is a golden waterway of most importance in China. But there are still some sections with poor navigation standards that impede the potential of the channel from being fully exploited. This paper aims to investigate the possibility of navigation capacity improvement through the joint dispatching optimization of the controlled reservoir group in the upper Yangtze River. The construction and operation situations of the controlled reservoir group are introduced, and the contribution of the current joint dispatching scheme to the Yangtze River Waterway is then analysed. Based on the growing demand for inland water transportation, the possibility of navigation capacity improvement through the joint dispatching optimization is further investigated. The results show that the channel dimension of Yibin-Chongqing and Yichang-Chenglingji section has improved to a certain degree under the current joint dispatching mode, further promotion is possible through the optimization of joint dispatching for those years when the amount of suppliable water during dry seasons is much greater than the shipping demand. Policy suggestions on joint dispatching are finally proposed.
\end{abstract}

\section{Introduction}

The Yangtze River is the most important east-west axis in the national land development strategy of China, and it is also famous as a golden waterway with a total length of $2838 \mathrm{~km}$ that extends from west to east and radiate out to both north and south. The navigation condition has improved significantly in recent years with construction of a series of large-scale projects such as the Three Gorges Dam and the Yangtze Estuary deep water channel regulation project. According to statistics, the freight volume of the Yangtze River has ranked world No. 1 for 13 consecutive years and even reached 25 ton in 2017.

However, the potential of this golden waterway has not been fully exploited partly because: 1) many shoals with curve and shallow characteristic, which largely affect the safety of shipping, lie in the upper reaches; 2) the channel depth of Yichang-Wuhan is lower than that of the upper and lower reaches, resulting that the ships sailing on this section have to undergo the load reduction. If large-scale channel regulation projects continue to be implemented, they may not only cause great changes of the river regimes which have negative impacts on the flood control safety, but also threaten the ecological security by disrupting the aquatic environment[1].

For decades, a group of huge reservoirs has been built in the main stream and tributaries of the upper Yangtze River, which is an important engineering system for water resources distribution in the basin. In general, its joint process of flood storage in rainy seasons and water replenishment in dry seasons has improved the navigation conditions[2]. However, the reservoirs are now primarily used for flood control and power generation, while they also consider the demands of water supply, navigation and ecology, etc. Based on the current dispatching mode of the reservoir group, the navigation benefit is far from satisfaction. Consequently, in order to utilize the water resources more efficiently and further promote the navigation capacity of the Yangtze River, it is necessary to investigate the optimization of joint dispatching.

This paper firstly introduces both construction and operation situations of the controlled reservoir group in the upper Yangtze River. The contribution of the current joint dispatching scheme to the Yangtze River Waterway is then analysed. Finally, based on the growing demand for inland water transportation, the possibility of the improvement of navigation capacity through the joint dispatching optimization is investigated and the related policy suggestions are proposed.

\section{Construction and dispatching of the controlled reservoir group}

\subsection{Construction situation}

$\overline{{ }^{a} \text { Corresponding author: chenyingjian@ }}$ cjwsjy.com.cn 
The Yangtze River is an important strategic base of clean energy in China, making great contributions to the sustainable development of regional economy. As the 24 large-scale hydro projects including the Three Gorges Dam were built and put into operation, the controlled reservoir group in the upper Yangtze River has taken shape, the distribution of which is shown in Figure 1. The total active storage and flood storage of this group are $5.15 \times 10^{10} \mathrm{~m}^{3}$ and $3.44 \times 10^{10} \mathrm{~m}^{3}$ respectively, showing a very strong regulating ability.

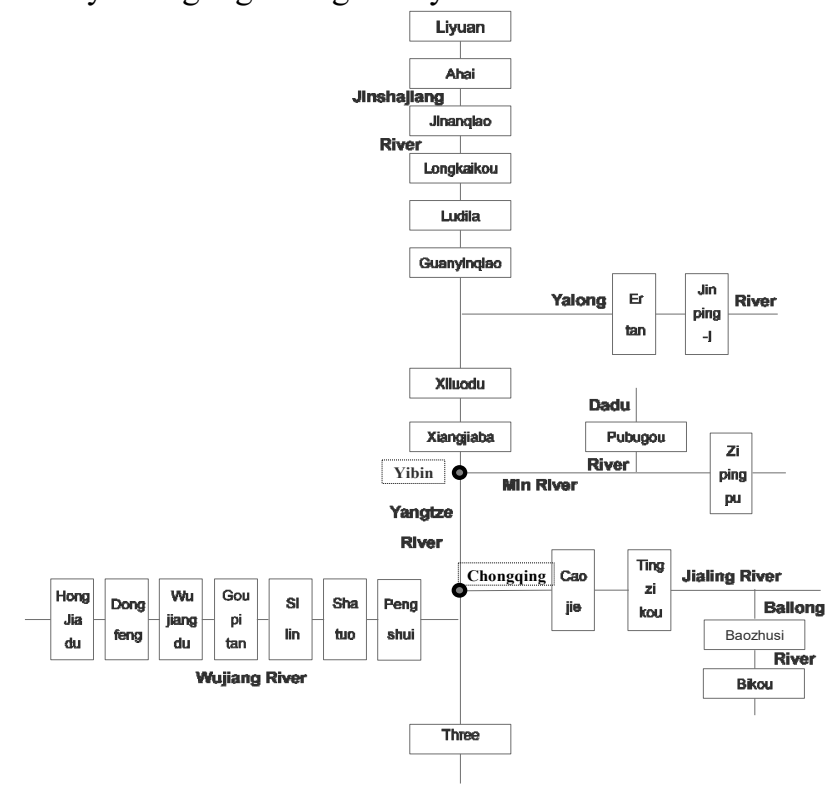

Figure 1. Diagram of the controlled reservoir group.

\subsection{Dispatching situation}

\subsubsection{The Three Gorges Reservoir}

Several years' practice showed that the dispatching of the Three Gorges Reservoir had a great impact on the Yangtze River. The dispatching rule for Three GorgesGezhouba cascade reservoirs was compiled in 2015 in order to promote a more comprehensive benefit from scientific dispatching. According to the rule, the profiting regulation should subject to the flood regulation, and it should be harmonized with water environment, water ecology and the long-term use of the reservoirs.

The explicit operation scheme of the Three Gorges Reservoir was also pointed out in the dispatching rule: 1) when the flood water needs not impounded in flood seasons, the reservoir water level should be confined at $145.0 \mathrm{~m}$ (the preflood limited water level); 2) the outflow of the reservoir in September and October should not less than $8000 \sim 10000 \mathrm{~m}^{3} / \mathrm{s}$ and $8000 \mathrm{~m}^{3} / \mathrm{s}$, respectively; 3 ) the outflow in November and December should ensure the water level at Miaozui (downstream of Gezhou Dam) not less than $39.0 \mathrm{~m}$ and should satisfy the guaranteed output requirement of the hydropower station; 4) if the reservoir is filled up(i.e., the reservoir water level reaches $175.0 \mathrm{~m}$ ) during water storage period, the outflow should be kept $6000 \mathrm{~m}^{3} / \mathrm{s}$ in January and
February and ensure the water level at Miaozui not less than $39.0 \mathrm{~m}$ from March to May.

\subsubsection{The controlled reservoir group}

The optimal dispatching rule for the controlled reservoir group was also compiled and operated to promote more comprehensive benefits from scientific joint dispatching. The dispatching principles include but not limited to: 1) the dispatching of reservoirs should be centralized to ensure the safety of flood prevention, water supply and watershed ecology in the whole basin; 2) the profiting regulation should subject to the flood regulation, and enough storage should be spared as planned in flood seasons; 3 ) the impoundment of reservoirs in dry seasons should be proceeded orderly and take the factors such as flood control, water supply, shipping, sediment transport into consideration; 4) the proper use of regulating storage should harmonize the needs of water supply, shipping, ecology, etc., and the outflow of reservoirs should not less than the lower limit of specified value[3].

\subsection{Calculation of the regulated outflow under the current dispatching scheme}

\subsubsection{Calculation method}

According to the dispatching principles and schemes mentioned above, the numerical model for joint dispatching of the controlled reservoir group in upper Yangtze River is established. The model regulates each reservoir orderly from upstream to downstream based on the self-undertaken comprehensive task and the joint dispatching scheme. The inflow of each reservoir equals to sum of the outflow of the corresponding upstream reservoirs and the runoff produced in the interval. This model also considers the impact of the backwater induced by the downstream reservoir on the tail water level of the hydropower station.

\subsubsection{Calculation of the regulated outflow}

The run-off series data from 1956 to 2012 are taken as the inflow conditions and then the regulated outflow of each reservoir is calculated. Here the averaged outflow of the Three Gorges Reservoir for every ten days with a 95\% assurance rate is plotted in Figure 2 as an example. The outflow under joint dispatching is lower than the natural run-off in flood seasons and larger than it in dry seasons, showing that the reservoir has significant capacity of water regulation, which to some extent can satisfy various demands for water resources during dry seasons in the middle and lower reaches of Yangtze 
River.

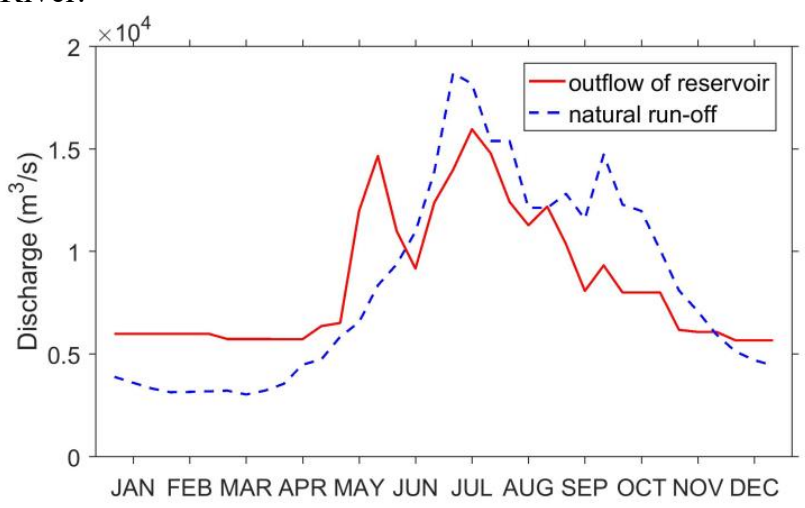

Figure 2. Averaged regulated outflow of the Three Gorges Reservoir with a $95 \%$ assurance rate.

\section{The impact of the current joint dispatching mode on the navigation capacity of the Yangtze River Waterway}

\subsection{Obstructions of the Yangtze River Waterway}

The Yangtze River Waterway extends from Shuifu (Yunnan Province) to Yangtze River estuary, of which the maintenance dimension in 2015 is shown in Table 1.

Table 1. The maintenance dimension of the Yangtze River Waterway in 2015.

\begin{tabular}{|c|c|c|c|}
\hline section & $\begin{array}{c}\text { distance } \\
(\mathrm{km})\end{array}$ & $\begin{array}{c}\text { maintenance dimension } \\
(\text { depth } \times \text { width } \times \text { radius, } \mathrm{m})\end{array}$ & $\begin{array}{c}\text { assurance } \\
\text { rate }(\%)\end{array}$ \\
\hline $\begin{array}{c}\text { Shuifu- } \\
\text { Yibin }\end{array}$ & 30.0 & $1.8 \times 40 \times 320$ & 95 \\
\hline $\begin{array}{c}\text { Yibin- } \\
\text { Chognqing }\end{array}$ & 384.0 & $2.9 \times 50 \times 560$ & 98 \\
\hline $\begin{array}{c}\text { Chongqing- } \\
\text { Fuling }\end{array}$ & 112.4 & $3.5 \times 100 \times 800$ & 98 \\
\hline $\begin{array}{c}\text { Fuling- } \\
\text { Yichang }\end{array}$ & 547.6 & $4.5 \times 150 \times 1000$ & 98 \\
\hline $\begin{array}{c}\text { Yichang- } \\
\text { Chenglingji }\end{array}$ & 396.0 & $3.5 \times 100 \times 750$ & 98 \\
\hline $\begin{array}{c}\text { Chenglingji } \\
\text {-Wuhan }\end{array}$ & 227.5 & $3.7 \times 150 \times 1000$ & 98 \\
\hline $\begin{array}{c}\text { Wuhan- } \\
\text { Anqing }\end{array}$ & 402.5 & $4.5 \times 200 \times 1050$ & 98 \\
\hline $\begin{array}{c}\text { Anqing- } \\
\text { Wuhu }\end{array}$ & 204.7 & $6.0 \times 200 \times 1050$ & 98 \\
\hline $\begin{array}{c}\text { Wuhu- } \\
\text { Nanjing }\end{array}$ & 101.3 & $9.0 \times 200 \times 1050$ & - \\
\hline $\begin{array}{c}\text { Nanjing- } \\
\text { Nantong }\end{array}$ & 263.6 & $10.5 \times 500 \times 1050$ & - \\
\hline $\begin{array}{c}\text { Nantong- } \\
\text { Taicang }\end{array}$ & 25.0 \\
\hline $\begin{array}{c}\text { Taicang- } \\
\text { Yangtze } \\
\text { estuary }\end{array}$ & 143.0 & $12.5 \times 350 \times 1050$ & - \\
\hline
\end{tabular}

It can be easily seen in Table 1 that there are two sections with poor standards in the upper and middle reaches of the Yangtze River:

1) The sections at upstream of Chongqing is complex in plane shape and there are multiple shoal risks distributed along the path, leading to insufficient water depth and rapid flow patterns. The technical grade of Yibin-Chongqing section in 2015 was Grade III, and the minimum depth was merely $2.9 \mathrm{~m}$, which was inconsistent with the navigation standards of the entire Yangtze River Waterway.

2) The Yichang-Wuhan section is tortuous, of which the riverbed evolves frequently and the water depth is shallow. Especially after the Three Gorges was built, the channel became unstable[4]. The maintenance depth of this section in 2015 was only $3.5 \sim 3.7 \mathrm{~m}$, which was lower than its upper and lower reaches.

\subsection{Analysis of the channel dimension of the controlled waterways in natural conditions}

The maintenance dimension of several waterways with shoal risks is further analysed. The basic information of these waterways is listed in Table 2. They are all located in the river sections Yibin-Chongqing and YichangChenglingji, which are considered to control the navigation scale of the upper and middle reaches of the Yangtze River due to the characteristics of "shallow, narrow and dangerous". The river sections at downstream of Chenglingji are not included in the scope of this study because: 1) they are far from the controlled reservoir group, and thus less affected by the joint dispatching than Yichang-Chenglingji; 2) Dongting Lake and the four rivers (Xiangjiang, Zishui, Yuanjiang and Lishui) flow into the main stream of Yangtze River at Chenglingji, but this water system is not controlled by the reservoir group of the upper Yangtze River.

Table 2. The basic information of the waterways focused in this study and their maintenance dimension under natural conditions.

\begin{tabular}{|c|c|c|c|}
\hline waterway & $\begin{array}{c}\text { length } \\
(\mathrm{km})\end{array}$ & location & $\begin{array}{c}\text { maintenance dimension in } \\
\text { natural conditions } \\
(\text { depth } \times \text { width, m) }\end{array}$ \\
\hline $\begin{array}{c}\text { Bingpanqi- } \\
\text { Huoyanqi }\end{array}$ & 47.0 & $\begin{array}{c}\text { Yibin- } \\
\text { Chongqing }\end{array}$ & \multicolumn{1}{|c|}{$2.9 \times 50$} \\
\hline Wenzhongba & 8.0 & $\begin{array}{c}\text { Yibin- } \\
\text { Chongqing }\end{array}$ & \multicolumn{1}{|c|}{$3.2 \times 60$} \\
\hline Taipiahe & 11.1 & $\begin{array}{l}\text { Yichang- } \\
\text { Chenglingji }\end{array}$ & $\begin{array}{l}\text { The construction of the } \\
\text { Three Gorges led to a } \\
\text { Yichang-Chenglingji } \\
\text { Yiverbed. Currently the } \\
\text { lowest discharge and the } \\
\text { corresponding water level } \\
\text { in natural conditions (i.e., } \\
\text { without the impact of } \\
\text { reservoirs) cannot meet } \\
\text { the design requirements } \\
\text { of shipping. }\end{array}$ \\
\hline
\end{tabular}

The method to analyse the maintenance dimension of the waterways listed in Table 2 without the impact of the 
reservoir group is given as follows: 1) investigate the lowest design navigable water level at the controlled point of each waterway in natural conditions (generally this level corresponds to a certain assurance rate); 2) collect the water level measurement data from water gauges along each waterway during flood, medium and dry periods; 3) draw the water surface curves under the design conditions by interpolation using the measured data and the design navigable water level at the controlled points; 4) calculate the water depth at each point of the waterways based on the topography which was mostly measured during 2015-2016; 5) draw the contour lines to determine the maintenance dimension of each waterway without the impact of dispatching. The results are also shown in Table 2.

\subsection{Analysis of the channel dimension under the current joint dispatching mode}

The channel dimension of the above-mentioned four controlled waterways with the impact of the current joint dispatching mode is then analysed using the similar method as in Section 3.2.

The waterway Huoyanqi-bingpanqi and Wenzhongba are both located in Yibin-Chongqing river section, the run-off of which approximates to sum of the outflow of the three upstream reservoirs - Xiangjiaba, Zipingpu and Pubugou with neglect of flow convergence and loss along the path. As calculated in Section 2.3 (not shown), the minimal run-off of this section under the current joint dispatching scheme is about $2822 \mathrm{~m}^{3} / \mathrm{s}$. In this circumstance, the channel dimensions of these two waterways are $3.2 \times 60 \times 800 \mathrm{~m}$ and $3.5 \times 70 \times 800 \mathrm{~m}$, respectively.

The waterways Lujiahe and Taipingkou are both located in Yichang-Chenglingji river section, the run-off of which approximates to the outflow of the Three Gorges Reservoir. As shown in Figure 2, the minimal run-off of this section is about $5700 \mathrm{~m}^{3} / \mathrm{s}$. In this circumstance, the channel dimensions of these two waterways are $3.5 \times 120 \times 1000 \mathrm{~m}$ and $3.5 \times 100 \times 1000 \mathrm{~m}$, respectively.

By comparison of the maintenance dimension of the two sections between the circumstances with and without joint dispatching, it can be concluded that the navigation capacity of these two sections has improved to a certain degree under the current joint dispatching mode.

It should be noted that the above analysis only considers the shoal terrains measured at a certain time (2015 or 2016). In general, due to the changing inflow of water/sand and the riverbed evolution induced by sedimentation and erosion, the river topography will be adjusted after each flood and dry season especially for river section Yichang-Chenglingji, which leads to the changes in the navigation scale of the channel. This study does not consider the impact of river evolution on the channel dimension for the time being. It is believed that the small-scale dredging and the construction of partial remediation buildings can be used to maintain the channel dimension during annual dry season.

\section{Thinking of the navigation capacity improvement by the joint dispatching optimization}

\subsection{Possibility Analysis}

Based on the requirements of the Yangtze River Economic Belt Development and the related waterway plannings, several improvement goals for the channel dimension of the two sections were proposed:

1) Yibin-Chongqing

Under the current joint dispatching, the maintenance depth of Yibin-Chongqing is $3.2 \mathrm{~m}$, which has already satisfied the planning standard in 2020 proposed by the transportation department. If it further rises to $3.5 \mathrm{~m}$, it can be coordinated with the current channel dimension of its downstream section Chongqing-Fuling. If the depth of $4.5 \mathrm{~m}$ is achieved, the 5,000-ton ship can navigate directly from the middle and lower reaches of the Yangtze River to Yibin through the Three Gorges Ship Lock.

2) Yichang-Chenglingji

Under the current joint dispatching, the maintenance depth of Yichang-Chenglingji is $3.5 \mathrm{~m}$. If it further rises to $4.0 \mathrm{~m}$, it will achieve the "13th Five-Year Plan" goal proposed by the transportation department. If the depth of $4.5 \mathrm{~m}$ is reached with the construction of $4.5 \mathrm{~m}$ Chenglingji-Wuhan upgrade project, the $4.5 \mathrm{~m}$-deep waterway can extend to the Three Gorges reservoir area from the Yangtze River estuary.

Here we further analyse how much discharge the reservoirs should approximately release to ensure the water depth of the two sections reaching the requirements proposed above. The results are shown in Table 3. For instance, if the channel depth of YichangChenglingji is expected to reach $4.0 \mathrm{~m}$, the required outflow of the Three Gorges Reservoir should be approximately $6500 \mathrm{~m}^{3} / \mathrm{s}$. The required amount of water during November to May is also calculated in Table 3.

Table 3. The required outflow and amount of water during November-May to improve the channel depth.

\begin{tabular}{|c|c|c|c|c|c|c|}
\hline section & \multicolumn{3}{|c|}{ Yibin-Chongqing } & \multicolumn{3}{c|}{ Yichang-Chenglingji } \\
\hline $\begin{array}{c}\text { assumed water } \\
\text { depth }(\mathrm{m})\end{array}$ & 3.5 & 4.0 & 4.5 & 4.0 & 4.5 & 5.0 \\
\hline $\begin{array}{c}\text { related reservoirs } \\
\text { Xiangjiaba+Zipingpu } \\
+ \text { +Pubugou }\end{array}$ & \multicolumn{4}{|c|}{ Three Gorges } \\
\hline $\begin{array}{c}\text { required outflow } \\
\left(\mathrm{m} / \mathrm{s}^{3}\right)\end{array}$ & 3000 & 5000 & 6000 & 6500 & 8000 & 9000 \\
\hline $\begin{array}{c}\text { required amount } \\
\text { of water during } \\
\text { Nov. to May } \\
\left(\mathrm{m}^{3}\right)\end{array}$ & 550 & 916 & 1100 & 1191 & 1465 & 1649 \\
\hline
\end{tabular}

Most of the reservoirs in the upper Yangtze River are primarily responsible for flood control and begin to store water after flood seasons. Generally, the water storage tasks are completed at the end of October. Based on the natural runoff data series from 1956 to 2012 (totally 56 years), the amount of water stored in the reservoirs at the end of October and the natural inflow from November to 
May are added together to calculate the total amount of suppliable water during dry seasons for every year. Then the results (not shown) are compared with the required amount of water for shipping which is shown in Table 2. The conclusions are drawn as follows: 1) For YibinChongqing section, the total water supply of Xiangjiaba, Zipingpu and Pubugou during dry seasons is greater than the water required to ensure the channel depth of $3.5 \mathrm{~m}$ every year, but even the year with the maximal water supply cannot guarantee the amount of water to meet the depth requirements of $4.0 \mathrm{~m}$ and $4.5 \mathrm{~m}$; 2) For YichangChenglingji section, the water supply of the Three Gorges Reservoir during dry seasons is greater than the water required to ensure the channel depth of $4.0 \mathrm{~m}$ every year, but there are still 3 years and 20 years that the suppliable water cannot guarantee the amount of water to meet the depth of $4.5 \mathrm{~m}$ and $5.0 \mathrm{~m}$, respectively.

For the years when the suppliable water is much greater than the shipping demand, the optimization of joint dispatching can generally promote navigation capacity to a large extent. However, for those years when the suppliable water is slightly greater or less than the shipping demand, the requirements of shipping can hardly be achieved even though the joint dispatching is optimized because of the requirements for comprehensive utilization of the water resources. Moreover, this situation will also not be greatly improved if the scale of the upstream reservoir group is further expanded.

\subsection{Policy suggestions}

Based on the above analysis, policy suggestions on the joint dispatching are proposed as follows:

1) Most of the controlled reservoirs in the upper Yangtze River were built with hydropower generation as a major development task, and their management departments are usually different. There is a dispatching contradiction among various profiting needs such as shipping, hydropower generation and water supply, so it is necessary to establish a unified dispatching management system and interest coordination mechanism across departments. To carry out the policy research based on the existing management system of the whole basin is recommended.

2) At the current stage, it is recommended to incorporate the shipping dispatching into the joint dispatching scheme and transform the shipping demand from original dispatching constraint to dispatching objective. The scheme is suggested to be compiled during flood seasons by the flood control and drought relief department based on the water storage situations of each controlled reservoir and the forecast of incoming water during dry seasons.

3) In order to maximize the comprehensive benefits, it is also recommended to coordinate the relationship between the economic benefit from hydropower generation and the social benefit from shipping and to establish a compensation mechanism. For example, policies on electricity price compensation in the shipping benefit areas and charge of ships passing the lock can be further explored.

4) The navigation capacity of the Yangtze River cannot be greatly promoted without any waterway regulation projects. In the river sections outside the ecologically sensitive areas of which the water depth is relatively shallow, the channel dimension can be also increased through some eco-friendly measures such as small-scale environmental dredging and ecological reef explosion, so as to reduce the shipping-oriented outflow of the reservoirs and effectively improve the comprehensive utilization of water resources. For the unstable river sections, it is possible to maintain the target dimension for a relatively long time by implementing the measures of ecological dam and training bank for stream guidance and channel stabilization.

\section{Conclusions}

The Yangtze River is the most important east-west axis in the national land development strategy of China, and it is also famous as a golden waterway with a total length of $2838 \mathrm{~km}$ that has the largest freight volume annually in the world. However, the potential of this golden waterway has not been fully exploited partly due to the poor navigation standards of some river sections. This paper aims to investigate the possibility of navigation capacity improvement through the joint dispatching optimization of the controlled reservoir group in the upper Yangtze River. The following conclusions are drawn:

1) Based on the current dispatching principles and schemes, the numerical model for joint dispatching of the controlled reservoir group in upper Yangtze River is established. By comparison of the maintenance dimension of the river sections Yibin-Chognqing and Yichang-Chenglingji between the circumstances with and without the joint dispatching, it can be concluded that the navigation capacity has improved to a certain degree under the current joint dispatching mode.

2) For Yibin-Chongqing section, it is possible to promote the channel depth to $3.5 \mathrm{~m}$ with the optimization of joint dispatching, but even the year with the maximal water supply cannot meet the channel depth requirements of $4.0 \mathrm{~m}$ and $4.5 \mathrm{~m}$. For YichangChenglingji section, it is possible to increase the channel depth to $4.0 \mathrm{~m}$ if the joint dispatching is optimized, but there are still a few years that the water supply can hardly satisfy the further promotion of the channel depth.

3) It should be noted that the possibility analysis in this paper is based on an ideal situation, that is, shipping is considered as relatively high priority. But in fact, it is just one of the major tasks of the controlled reservoirs, the optimization of joint dispatching cannot only meet the requirement of navigation improvement and neglect other demands. Further researches on joint dispatching and compensation mechanisms should be conducted to better harmonize various needs of shipping, flood control, hydropower generation, ecology, etc. 
4) The improvement of navigation capacity is a systematic project, it cannot be achieved only with a single measure. It is recommended to coordinate the implementation of various measures to make the Yangtze River a smooth, efficient, safe and green waterway.

\section{Acknowledgements}

Yingjian Chen and Fangkai Ma are both financially supported by The National Key Research and Development Program of China under Grant No. 2016 YFC0402005.

\section{References}

1. X. Niu, China Water Transport, 06, 10-12 (2015)

2. X. Zhang, J. Lu, L. Xing, J. Chen, Yangtze River, 49, 31-37 (2018)

3. G. Chen, Yangtze River, 44, 1-6 (2013)

4. M. Li, Port \& Waterway Engineering, 527, 156-160 (2017) 